\title{
High-strength scaffolds for bone regeneration
}

1 James Meredith*

Doctor, University of Sheffield, Sir Frederick Mappin Building, Sheffield, UK
2 Kajal K. Mallick

Doctor, The Warwick Manufacturing Group (WMG), University of Warwick, Coventry, UK
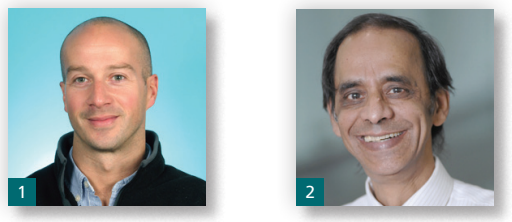

Repair of large skeletal defects that are intrinsic to skeletal stability represents the greatest challenge for orthopaedic surgeons. ${ }^{1}$ Despite extensive research to replicate the mechanical properties of bones in a synthetic alternative none are commercially available. This research reports a practical solution to this challenge by applying the extrusion process used for the production of ceramic exhaust catalysts to calcium phosphate bone graft substitutes. Clay-like hydroxyapatite (HA) pastes formed in a high-shear mixer were extruded through a complex die, dried and finally fired to form highly porous and strong monoliths. Five different samples were produced with differing wall thickness, cell pitch and porosity. The resulting HA monoliths had primary axis compressive strength of 142-265 MPa and compressive modulus of 3.9-4.4 GPa. These values well correspond to cortical bone

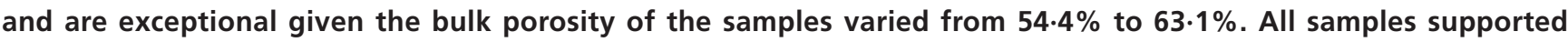
the proliferation of MG63 cells with only a marginal difference between the samples. It is expected that calcium phosphate-based extruded monoliths will provide a possible commercial alternative to autograft and allograft for large structural bone defects.

\section{Introduction}

Bone defects arising from disease, trauma, infection or genetic abnormality are reconstructed with non-biodegradable materials such as stainless steel or titanium to restore skeletal function. ${ }^{2,3}$ These materials have been associated with long-term problems such as loosening, ${ }^{4}$ peri-prosthetic fracture and infection. ${ }^{5}$ The modern approach is marked by a shift in emphasis from replacement to regeneration of tissue. ${ }^{6,7}$ This is achieved by way of human- or animal-derived grafts (autograft, allograft or xenograft), bone graft substitute (BGS) materials, growth factors ${ }^{8}$ or bioinorganics. ${ }^{9}$ The drawbacks associated with human- and animal-derived grafts such as limited availability, high cost, poor remodelling, donor site morbidity, delayed healing and disease transmission have driven extensive research into synthetic alternatives. ${ }^{10-13}$ The principal advantages of BGSs are unlimited supply, ease of sterilisation and storage, predictable mechanical properties, excellent bone in-growth and moderate cost. ${ }^{14,15}$
Bone defects can be categorised into those that are intrinsic to skeletal stability and those that are not. Currently, there are numerous commercially available low-strength, void-filling BGS products but none are indicated to offer structural support to the skeleton. ${ }^{16-18}$ Thus, there is an urgent need for BGSs that can replace allogenous or autogenous grafts in large defects, for example, in resections for infection or tumour. In these instances, bone grafts can be as large as $20 \mathrm{~cm}$ and their locations (joints, spine and long bones) require them to bear load and function with instrumentation to maintain the stability of the skeleton. ${ }^{2,19-21}$ Non-structural biomaterials can repair segmental defects in combination with instrumentation such as plates and screws but these require an additional retrieval procedure. ${ }^{22} \mathrm{~A}$ BGS material with the strength of cortical bone will benefit many patients and be particularly useful in spinal arthrodesis where high strength and osteoinductivity are essential to ensure rapid fusion..$^{23,24}$ 
A structural BGS should match the mechanical properties of native bone and remain stable once implanted, that is, not expand or contract thereby affecting bony integration. ${ }^{25}$ There is a large variation in the reported properties of native bone due to its anisotropy, person-toperson variation, use of aged or osteoporotic bone and the anatomical location of the tested specimen. ${ }^{26}$ The compressive modulus for cortical bone lies in the range of 5-35 GPa and compressive strength lies in the range of 50-215 MPa. The tensile modulus varies from 4 to $30 \mathrm{GPa}$ and tensile strength varies from 90 to $170 \mathrm{MPa} .{ }^{26-28}$ The ideal mechanical properties for a BGS will vary according to application area but a structural BGS should match those set out above for cortical bone $^{24}$ in order to avoid stress shielding. Maintenance of normal physiological levels of stress, strain and deflection is also important in enhancing the speed of repair. ${ }^{10}$

A BGS must provide a porous framework to which blood vessels and bone can invade in order to heal the defect. The porosity allows for the diffusion of nutrients, metabolites and gases as well as removal of waste from cell activity. ${ }^{29,30}$ Many aspects of porosity are documented to influence attachment and long-term survival of cells including the maximum and minimum pore size, the size distribution, pore shape, volume fraction, nature and interconnectivity of the pores, as well as the density and stiffness of the struts between pores. ${ }^{10,31}$ The minimum pore size is regarded to be $100 \mu \mathrm{m}$ due to cell size, migration requirements and nutrient transport. However, pore sizes of $300 \mu \mathrm{m}$ and larger are recommended in order to facilitate enhanced formation of de novo bone and blood capillaries ${ }^{32}$ as well as accommodate osteons that have a size of approximately $220 \mu \mathrm{m} .^{33}$

The pores within a BGS must be fully interconnected to facilitate in-growth of blood vessels and eventual formation of new bone. ${ }^{29}$ Bone can only be formed by deposition on a suitable surface that is within $200 \mu \mathrm{m}$ of a blood supply so that it can receive nutrients by way of diffusion. ${ }^{14,34-36}$ The bulk porosity ranges from $8 \%$ to $28 \%{ }^{27}$ for cortical bone and from $30 \%$ to $90 \%{ }^{28}$ for cancellous bone. High bulk porosity will allow for rapid infiltration by blood vessels and cells but also lead to low mechanical strength. Thus there is a trade-off to be made between high porosity and high strength. ${ }^{24}$

Bone scaffolds are intended to degrade in vivo at a rate proportional to the deposition of de novo bone that will depend on the age and health of the patient as well as the anatomical location and proximity to blood flow. ${ }^{29,30}$ Hence, the biomaterials available are limited to a small range of bioceramics, biopolymers and metals. The most commonly available bioceramics are based on calcium phosphates, for example, hydroxyapatite (HA) or tricalcium phosphate (TCP). ${ }^{37}$ They have compressive strength and modulus that closely match those of native bone but are brittle with poor tensile strength. ${ }^{34}$ However, they have excellent osteoconductivity and the ability to elute drugs at the implant site. ${ }^{38}$ Although research has established that macrostructure, microstructure and chemical composition are critical to their osteoinductive potential, the precise controlling mechanisms have not been fully characterised..$^{11,39-45}$

The present work is focused on a novel application of ceramic monolith extrusion for bone tissue engineering (BTE). A ceramic monolith is a porous, unitary ceramic body. Its method of fabrication yields both remarkably high porosity and strength, a combination highly sought after in BGS materials. The process to manufacture ceramic monoliths has been developed over the past 40 years for manufacture of the cordierite exhaust catalysts and is now well established. In 1971, Rodney D. Bagley invented a practical honeycomb extrusion die known as the Corning Celcor ${ }^{\circledR}$ die (Corning, NY). ${ }^{46}$ This consisted of a steel plate with an array of feed holes drilled into the back of the plate and a set of milled slits into the front of the plate. In this way, the holes fed material into the slits and the slits defined the form of the final honeycomb. ${ }^{47}$ The extrusion process creates a great deal of porosity by purely mechanical means and there is no need for any chemistry, pore formers or etchants.

The process contains five main steps: (a) mixing of the raw oxides in order to allow complete reaction during heating, $(b)$ plasticising or kneading of the ceramic powder, binders and a liquid to form a clay-like paste, $(c)$ extrusion of the paste through a die, $(d)$ drying the moisture from the extruded monolith and (v) firing to transform the raw materials into a monolithic substrate. ${ }^{48-50}$ In the present study, a range of extruded HA monoliths were manufactured and characterised for their suitability as a structural BGS. The hypothesis was that the extrusion process would enable manufacture of a novel BGS material with high strength combined with high porosity.

\section{Materials and methods}

\subsection{Raw materials}

HA was selected as the benchmark material because of its extensive previous clinical use. ${ }^{51-53}$ Three HA powders HAP 100, HAP 200 and HAP 300 with mean particle diameter and specific area as shown in Table 1 were purchased from Taihei-Kagaku Corporation, Japan.

\subsection{Manufacture of HA pellets}

In order to establish the compressive strength and porosity for each raw powder a series of pellets were compressed into cylinders at $2 \times 10^{6} \mathrm{~kg} / \mathrm{m}^{2}$ and $20 \times 10^{6} \mathrm{~kg} / \mathrm{m}^{2}$. These were sintered at $1150^{\circ} \mathrm{C}$ for $2 \mathrm{~h}$. Once cool each sample was measured for firing shrinkage by measuring the change in length of the sample with a digital vernier

\begin{tabular}{lccc} 
& HAP & HAP & HAP \\
& $\mathbf{1 0 0}$ & $\mathbf{2 0 0}$ & $\mathbf{3 0 0}$ \\
\hline Mean particle diameter: $\mu \mathrm{m}$ & 24 & 9 & 19 \\
Specific surface area: $\mathrm{m}^{2} / \mathrm{g}$ & $50-60$ & $5-10$ & $70-90$ \\
\hline
\end{tabular}

Table 1. Properties of the raw HA powders 
Bioinspired, Biomimetic and Nanobiomaterials Volume 4 Issue BBN1
High-strength scaffolds for bone

regeneration

Meredith and Mallick caliper (Mitutoyo, Japan). Porosity and average pore diameter were assessed by mercury porosimetry (AutoPore IV 9510, Micromeritics (Cumming, GA)). Apparent density was measured by mercury displacement (Archimedes method). Compressive strength was measured using an Instron 5800R (Instron, High Wycombe, UK) with ground plattens and a compression rate of $1 \mathrm{~mm} / \mathrm{min}$. Material phase purity was assessed by X-ray diffraction (XRD) (Phillips diffractometer PW1710, PANalytical, UK).

\subsection{Extrusion of HA monoliths}

The physical dimensions of a monolith are described by cell pitch (CP) and wall thickness (WT) as shown in Figure 1. The HA powders were mixed with a methylcellulose binder (A4M, Dow Chemical Co. (Staines, UK)) and deionised water in a high-shear Z-blade mixer (LABZ Winkworth, UK) and mixed until a homogenous, highviscosity, clay-like paste had formed. The paste was loaded into a proprietary extrusion machine with the appropriate die fitted. Two different dies were available to control the $\mathrm{CP}$ and WT of the extruded monoliths. Die 1 with $\mathrm{WT}=0.3 \mathrm{~mm}$ and $\mathrm{CP}=1.5 \mathrm{~mm}$ and die 2 with $\mathrm{WT}=0.7 \mathrm{~mm}$ and $\mathrm{CP}=3.0 \mathrm{~mm}$. The paste was then extruded, cut to length using a cheese wire and dried in air for $24 \mathrm{~h}$ prior to being fired according to Table 4.

WT and $\mathrm{CP}$ of the extruded monoliths were measured using a Nikon (Kingston upon Thames, UK) Eclipse LV100D-A optical microscope combined with Buehler (Lake Bluff, IL) Omninet modular digital imaging software. The median pore diameter and pore volume were obtained using mercury porosimetry (AutoPore IV 9510, Micromeritics). Bulk porosity was calculated for five specimens of each sample using the formula below. While $\emptyset_{\text {ave }}$ is the average sample diameter, $h_{\text {ave }}$ is the average sample height which was measured using a digital vernier caliper (Mitutoyo, Japan). Sample mass in each case was measured to four decimal places and $\rho_{\text {theoretical }}$ for HA was $3 \cdot 16 \mathrm{~g} / \mathrm{cm}^{3}$.

$$
\text { Bulk porosity }=1-\left(\frac{\text { Samplemass }}{\left(\left(\pi \times\left(\frac{\varnothing_{\text {ave }}}{2}\right)^{2} \times h_{\text {ave }}\right) / \rho_{\text {theoretical }}\right)}\right) \times 100
$$

The A-axis is the primary axis in line with the extrusion direction. The A-axis compressive strength was measured using an Instron 5800R; five specimens of each sample were tested for statistical significance. The sample size for die 2 samples was three cells by three cells by $20 \mathrm{~mm}$ height, and for the die 1 samples $15 \mathrm{~mm}$ diameter by $5 \mathrm{~mm}$ height. The three-point bending strength was measured over a $10-\mathrm{mm}$ span with a sample size of $20 \mathrm{~mm}$ (length) x $4 \mathrm{~mm}$ (width) $\times$ 'wall thickness' .

\subsection{Biological characterisation}

\subsubsection{Sample preparation}

Twelve specimens of each sample A-E were sterilised by autoclaving at $135^{\circ} \mathrm{C}$ for $1 \mathrm{~h}$ then soaked in media for 24 ours prior to the experiment. The samples (A-E) were then loaded into four sets of 12 well culture plates, one for each time point.

\subsubsection{MG63 cell culture}

MG63 human osteosarcoma cells donated by Professor Martin Hewison, UCLA, USA, were cultured in Earles minimum essential medium (MEM) containing glutamax, $1.5 \mathrm{~g} / 1$ of sodium

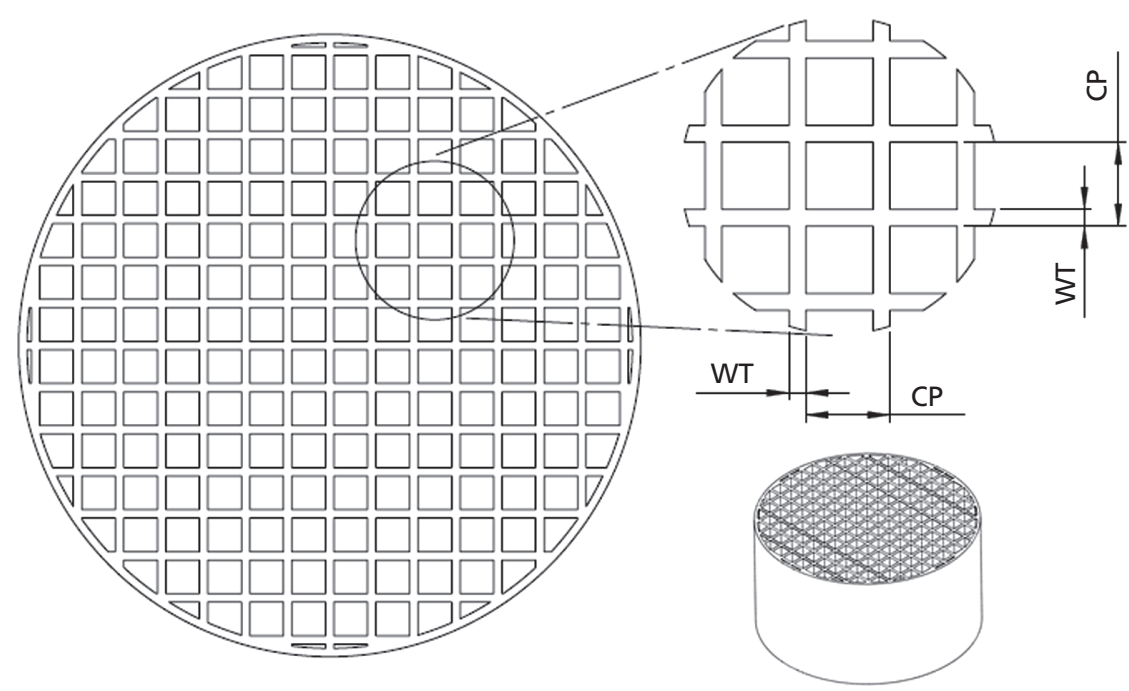

Figure 1. A schematic of a ceramic monolith highlighting the dimensions that relate to WT and CP 
bicarbarbonate and $1 \mathrm{mM}$ pyruvate supplemented with $10 \%$ foetal calf serum and 1\% non-essential amino acids (NEAA). The cells were subdivided and seeded onto the sterile samples with $1 \times 10^{5}$ cells.

\subsubsection{Cell number}

MTT assay is a simple flour metric assay. The metabolic conversion of MTT (3-(4,5-dimethylthiazol-2-yl)-2,5-diphenyltetrazoliumbromide) can be used to monitor the biochemical activity of cells. The MTT assay was performed at day 3, 6, 9 and 13. At each time point one set of triplicate samples was subjected to the MTT assay to assess cell proliferation. Briefly, the samples were removed from the culture plate, washed with phosphate-buffered saline (PBS; Sigma-Aldrich (Gillingham, UK)) at $37^{\circ} \mathrm{C}$ and added to a new culture plate. $1 \mathrm{ml}$ of MTT (Sigma) was added to each well to cover the sample and the culture plate was incubated for $30 \mathrm{~min}$ at $37^{\circ} \mathrm{C}$. After incubation the samples were removed and blotted dry before adding to a new culture plate with $1 \mathrm{ml}$ of dimethyl sulfoxide (DMSO; Sigma) to lyse the cells and release the MTT metabolite. This was swilled over the samples to remove the purple formazan and transfer the colour into the DMSO solution. A sample of the coloured DMSO was then transferred to five wells of a 96 well culture plate and the optical density (OD) quantified at $550 \mathrm{~nm}$ in a spectrophotometer (MR 7000, Dynatech, UK). Cell number was determined using a linear correlation between absorbance and cell concentration.

\section{Results}

\subsection{HA pellets}

The results from the pellets are presented in Table 2. There is a significant difference in compressive strength and porosity between the samples moulded at $2 \times 10^{6} \mathrm{~kg} / \mathrm{m}^{2}$ and $20 \times 10^{6} \mathrm{~kg} /$ $\mathrm{m}^{2}$. The higher moulding pressure largely eliminates any porosity and delivers a high compressive strength $(\sim 800 \mathrm{MPa})$. The lower moulding pressure was chosen as both the porosity $(18 \cdot 6 \%-50 \cdot 2 \%)$ and compressive strength (70-204 MPa) were within the range considered desirable for BGS. The low compressive strength of HAP 300 excluded it from further consideration.

The XRD analysis demonstrated that in each case the peaks match with the Joint Committee on Powder Diffraction Standards (JCPDS) pattern and that the phase purity and crystallinity of the HA have been maintained during sintering.

\subsection{Extruded HA monoliths}

An experiment was so designed as to determine the effect of physical dimensions (CP, WT) and material on the mechanical and biological properties of the monoliths as shown in Table 3. The samples were extruded using two different pastes both of which were found to extrude satisfactorily through the dies. Paste 1 used a 50:50 mix of HAP 100 and HAP 200 whereas paste 2 used HAP 200 only. Further details of the paste mix and firing details for each sample are shown in Table 4.

\begin{tabular}{|c|c|c|c|c|c|c|}
\hline Material & $\begin{array}{l}\text { HAP } \\
100\end{array}$ & $\begin{array}{l}\text { HAP } \\
200\end{array}$ & $\begin{array}{l}\text { HAP } \\
300\end{array}$ & $\begin{array}{l}\text { HAP } \\
100\end{array}$ & $\begin{array}{l}\text { HAP } \\
200\end{array}$ & $\begin{array}{l}\text { HAP } \\
300\end{array}$ \\
\hline $\begin{array}{l}\text { Moulding } \\
\text { pressure: kg/m² }\end{array}$ & $0 \cdot 2$ & 0.2 & 0.2 & 2 & 2 & 2 \\
\hline $\begin{array}{l}\text { Firing } \\
\text { shrinkage: \% }\end{array}$ & 29 & 17 & 23 & 22 & 17 & 22 \\
\hline $\begin{array}{l}\text { Open } \\
\text { porosity: \% }\end{array}$ & $18 \cdot 6$ & $40 \cdot 4$ & $50 \cdot 2$ & 0.03 & $1 \cdot 3$ & 0.05 \\
\hline $\begin{array}{l}\text { Pore } \\
\text { diameter: } \mu \mathrm{m}\end{array}$ & $1 \cdot 5$ & $5 \cdot 0$ & $9 \cdot 0$ & - & - & - \\
\hline $\begin{array}{l}\text { Apparent } \\
\text { density: } \mathrm{g} / \mathrm{cm}^{3}\end{array}$ & $3 \cdot 15$ & $3 \cdot 14$ & $3 \cdot 14$ & $3 \cdot 14$ & $2 \cdot 91$ & $2 \cdot 91$ \\
\hline $\begin{array}{l}\text { Compressive } \\
\text { strength: } \mathrm{MPa}\end{array}$ & 204 & 200 & 70 & 883 & 784 & 780 \\
\hline
\end{tabular}

Table 2. Results from experiments on HA pellets

\begin{tabular}{lll} 
& Die 1 & Die 2 \\
Paste 1 & A & B \\
Paste 2 & C, D & E \\
\hline
\end{tabular}

Table 3. HA scaffold monolith configuration details

\begin{tabular}{lccccc}
$\begin{array}{l}\text { Sample } \\
\text { number }\end{array}$ & A & B & C & D & E \\
$\begin{array}{l}\text { HAP100/200 } \\
\text { (by mass) }\end{array}$ & $50 / 50$ & & $0 / 100$ & \\
$\begin{array}{l}\text { Binder: mass \% } \\
\text { Kneading water: }\end{array}$ & 10 & & & 15 & \\
mass \% & 46 & & 50 & \\
$\begin{array}{l}\text { Firing } \\
\text { temperature: }{ }^{\circ} \mathrm{C}\end{array}$ & 1150 & 1150 & 1150 & 1200 & 1200 \\
$\begin{array}{l}\text { Cooling rate: } \\
{ }^{\circ} \mathrm{C} / \mathrm{h}\end{array}$ & 30 & 30 & 30 & 30 & 30 \\
\hline
\end{tabular}

Table 4. Paste mix details

Optical micrographs of the extruded HA samples are displayed in Figure 2 which demonstrates the difference between die 1 and die 2. The results for the physical characterisation are highlighted in Table 5. The WT of samples A, C and D varied from 0.28 to $0.33 \mathrm{~mm}$ and for samples $\mathrm{B}$ and $\mathrm{E}$ between 0.58 and $0.63 \mathrm{~mm}$. The CP for A, C and D varied from 1.08 to $1.16 \mathrm{~mm}$ and for samples B and $\mathrm{E}$ between 2.48 and $2.53 \mathrm{~mm}$.

Wall porosity refers to the level of porosity in the material that constitutes the walls and the bulk porosity refers to the overall porosity of the monolith and includes the empty cells. Both samples A and B (paste 1 sintered at $1150^{\circ} \mathrm{C}$ ) have a wall porosity of $15 \%$, sample $\mathrm{C}$ (paste 2 sintered at $1150^{\circ} \mathrm{C}$ ) has $33 \%$ and samples D and $\mathrm{E}$ (paste 2 sintered at $1200^{\circ} \mathrm{C}$ ) have $22 \%$. A-axis compressive strength is related to wall porosity where higher porosity leads to lower strength. Hence sample $\mathrm{C}$ 
Bioinspired, Biomimetic and Nanobiomaterials Volume 4 Issue BBN1
High-strength scaffolds for bone

regeneration

Meredith and Mallick

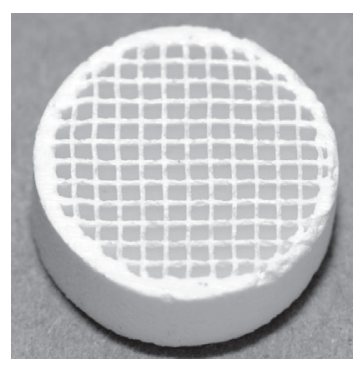

(a)

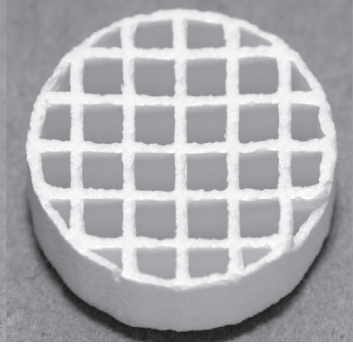

(b)

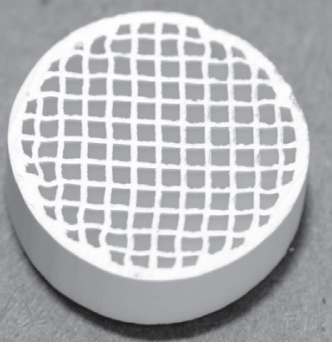

(c)

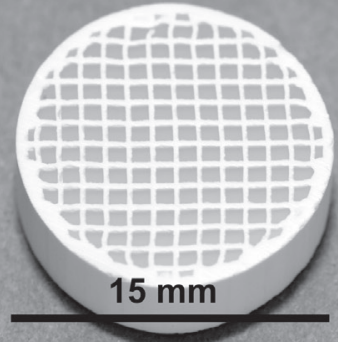

(d)

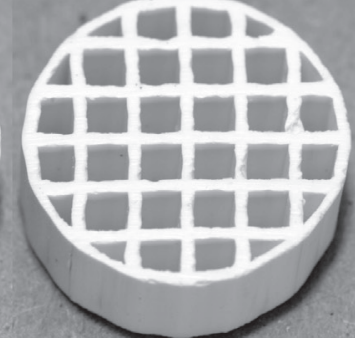

(e)

Figure 2. Optical micrographs of samples A-E demonstrating their physical characteristics

$\begin{array}{lccccc}\text { Sample number } & \text { A } & \text { B } & \text { C } & \text { D } & \text { E } \\ \text { WT - wall thickness: mm } & 0.28 & 0.58 & 0.33 & 0.28 & 0.63 \\ \text { CP - cell pitch: mm } & 1.08 & 2.48 & 1.16 & 1 \cdot 10 & 2.53 \\ \text { Wall porosity: \% } & - & 15 & 33 & - & 22 \\ \text { Bending strength: MPa }(\sigma) & - & 46(3) & 33(5) & - & 46(7) \\ \text { E-modulus bending: GPa }(\sigma) & - & 57(4) & 29(4) & - & 46(5) \\ \text { A-axis compressive strength: MPa }(\sigma) & 265(29) & 243(40) & 142(8) & 233(52) & 263(63) \\ \text { E-modulus A-axis compressive strength: GPa }(\sigma) & 4.1(0.1) & 4.4(0.1) & 3.2(0.1) & 3.9(0.5) & 4.2(0.3) \\ \text { Median pore diameter: } \mu \mathrm{m}) & 0.23 & 0.25 & 0.40 & 0.43 & 0.35 \\ \text { Pore volume: cc/g } & 0.036 & 0.047 & 0.124 & 0.066 & 0.079 \\ \text { Bulk porosity: \% } & 54.4 & 59.5 & 63.1 & 58.3 & 61.6\end{array}$

Table 5. Physical properties for the samples

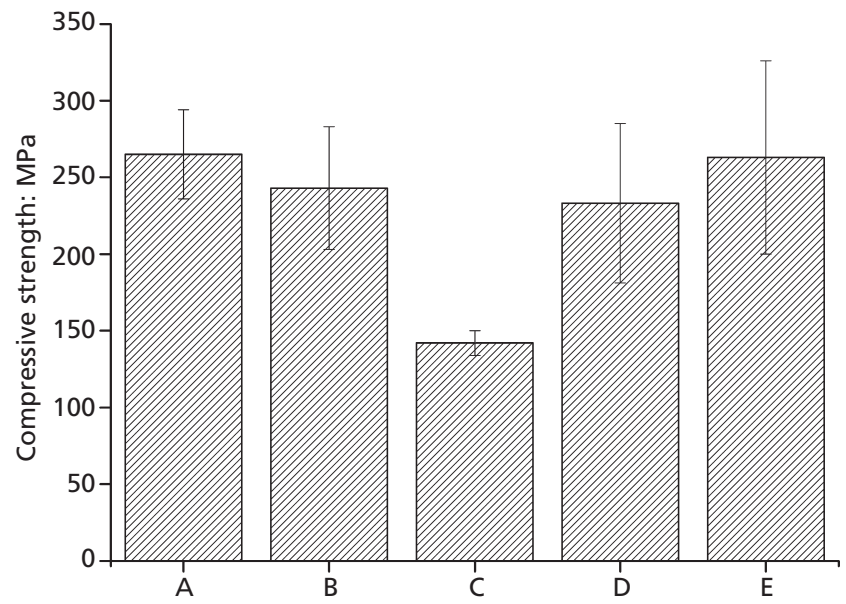

Figure 3. A-axis compressive strength of extruded HA monoliths

has strength of 142MPa against 233-265 MPa for samples A, B, D and E. The A-axis compressive strength and modulus are plotted in Figures 3 and 4 to graphically demonstrate the results. The results demonstrate that all the samples A, B, D and E exhibit similar mechanical properties while $\mathrm{C}$ is approximately $50 \%$ weaker. The samples show compressive strength within the range of cortical bone and stiffness that at $4.4 \mathrm{GPa}$ $(\max )$ is close to the lower end of cortical bone at $5 \mathrm{GPa}$.

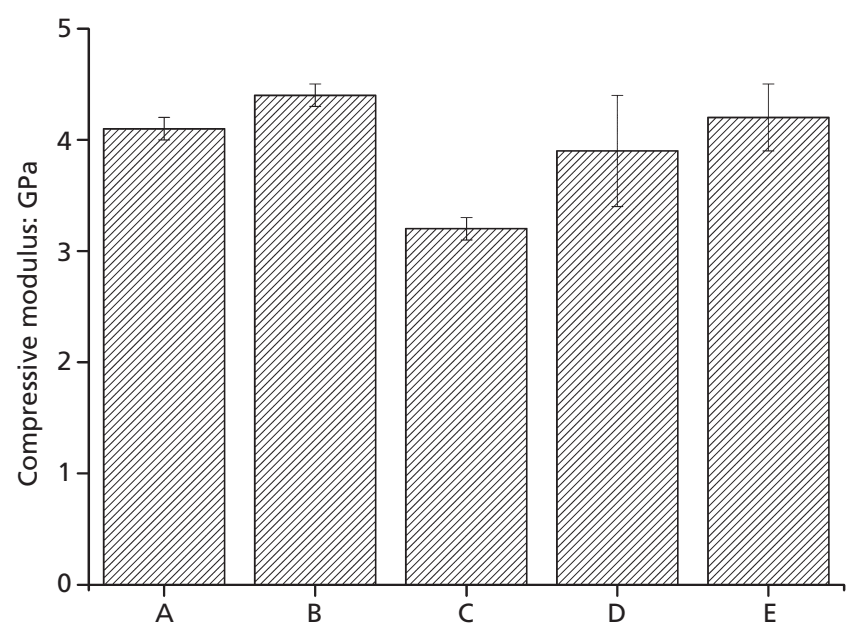

Figure 4. A-axis compressive modulus of extruded HA monoliths

The XRD analysis demonstrated that each material was $100 \%$ phasepure HA and matches the published standard JCPDS reference pattern (09-0432) for HA. Scanning electron microscopy (SEM) (Zeiss Sigma (Welwyn Garden City, UK)) of the samples revealed the microstructural details of each sample and how the processing conditions have affected them (Figure 5). Sample C has visibly greater microporosity than the other samples. 
Bioinspired, Biomimetic and Nanobiomaterials

Volume 4 Issue BBN1
High-strength scaffolds for bone

regeneration

Meredith and Mallick

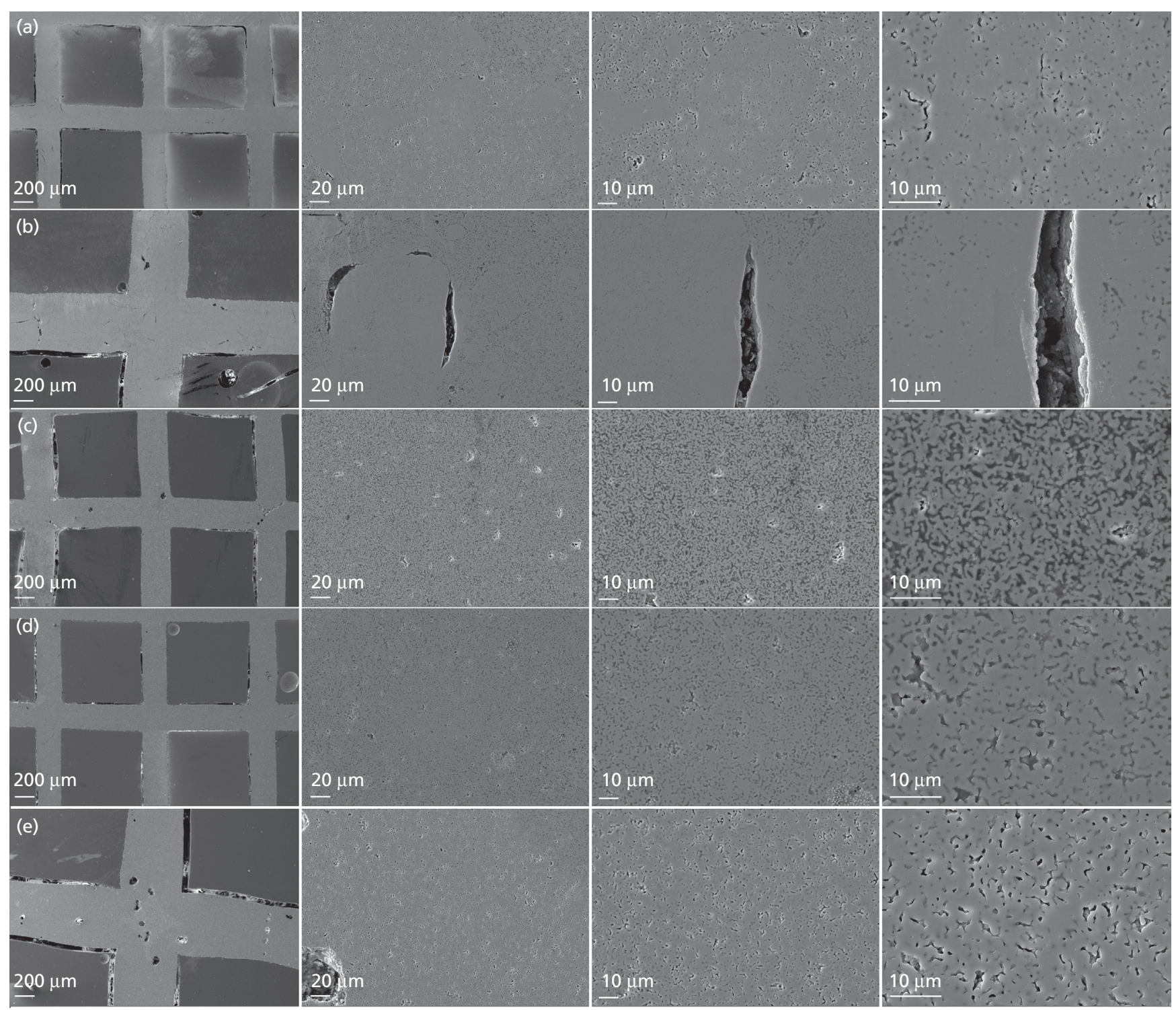

Figure 5. SEM images of polished samples demonstrating microstructural details of the walls in each sample

\subsection{Cell count assay}

MTT results for cells on samples are presented in Figure 6. Analysis of variance (ANOVA) was carried out using SPSS (IBM). Pairwise comparisons were conducted using the Tukey multiple comparison procedure to determine if samples A-E were statistically different from one another. There was no statistically significant difference between samples until day 6 where $\mathrm{D}$ was significantly greater than $\mathrm{E}(p<0 \cdot 05)$. There was no difference between samples on day 9 but on day $13 \mathrm{~A}>\mathrm{C}(p<0.05), \mathrm{A}>\mathrm{E}(p<0.05), \mathrm{D}>\mathrm{E}(p<0.05)$ and $\mathrm{B}>\mathrm{E}(p<0 \cdot 05)$.

The MTT results for cells remaining in culture wells are displayed in Figure 7. In order to compare the empty control directly with the results from each sample the results from 'cell on samples' and 'cells in wells' were summed and plotted in Figure 8.

\section{Discussion}

The moulding pressure for the HA pellets had a large effect on porosity and strength. A moulding pressure of $2 \times 10^{6} \mathrm{~kg} / \mathrm{m}^{2}$ delivered porosity in the range of $18.6 \%-50.2 \%$ and strength in the range of 70-205 MPa. These properties were more desirable for a BGS than those found at $20 \times 10^{6} \mathrm{~kg} / \mathrm{m}^{2}$. The apparent density for HAP 200 and HAP 300 moulded at $20 \times 10^{6} \mathrm{~kg} / \mathrm{m}^{2}$ was only $2.91 \mathrm{~g} / \mathrm{cm}^{3}$, lower than the expected $3.16 \mathrm{~g} / \mathrm{cm}^{3}$, which indicated the presence of trapped pores within the samples. Overall the results 


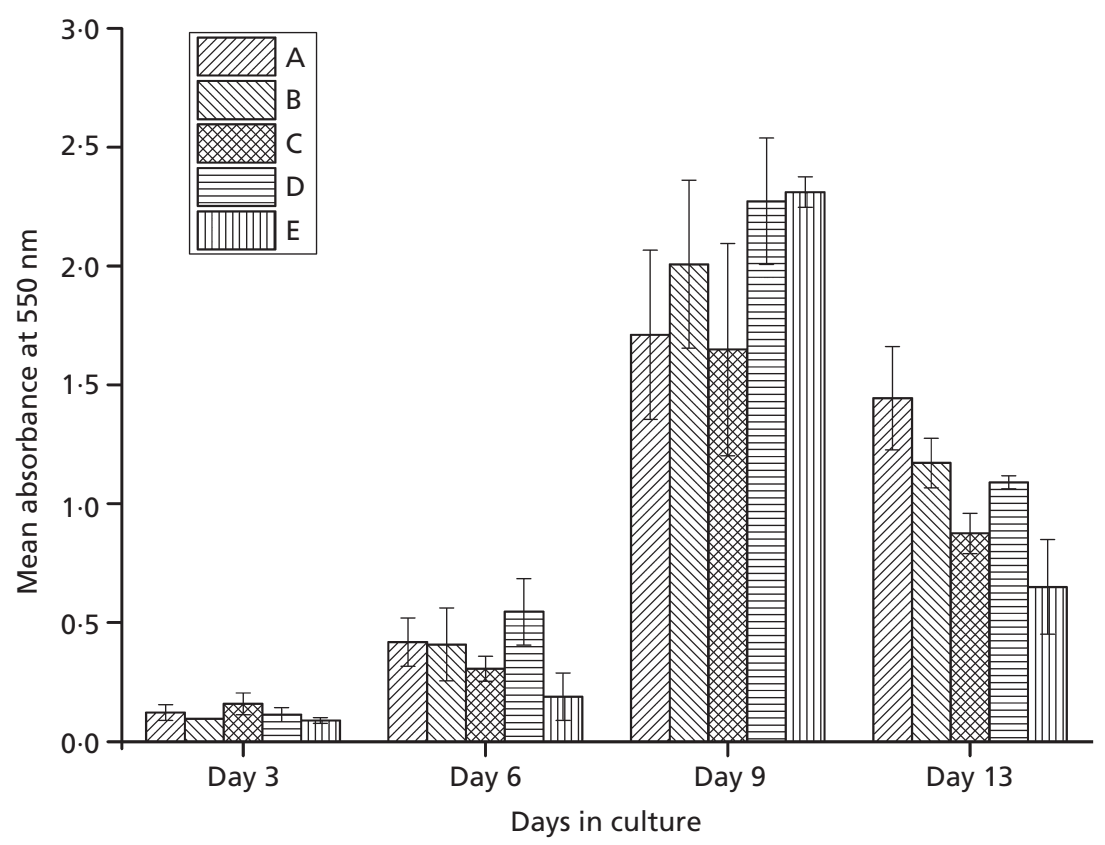

Figure 6. MTT results for cells on samples

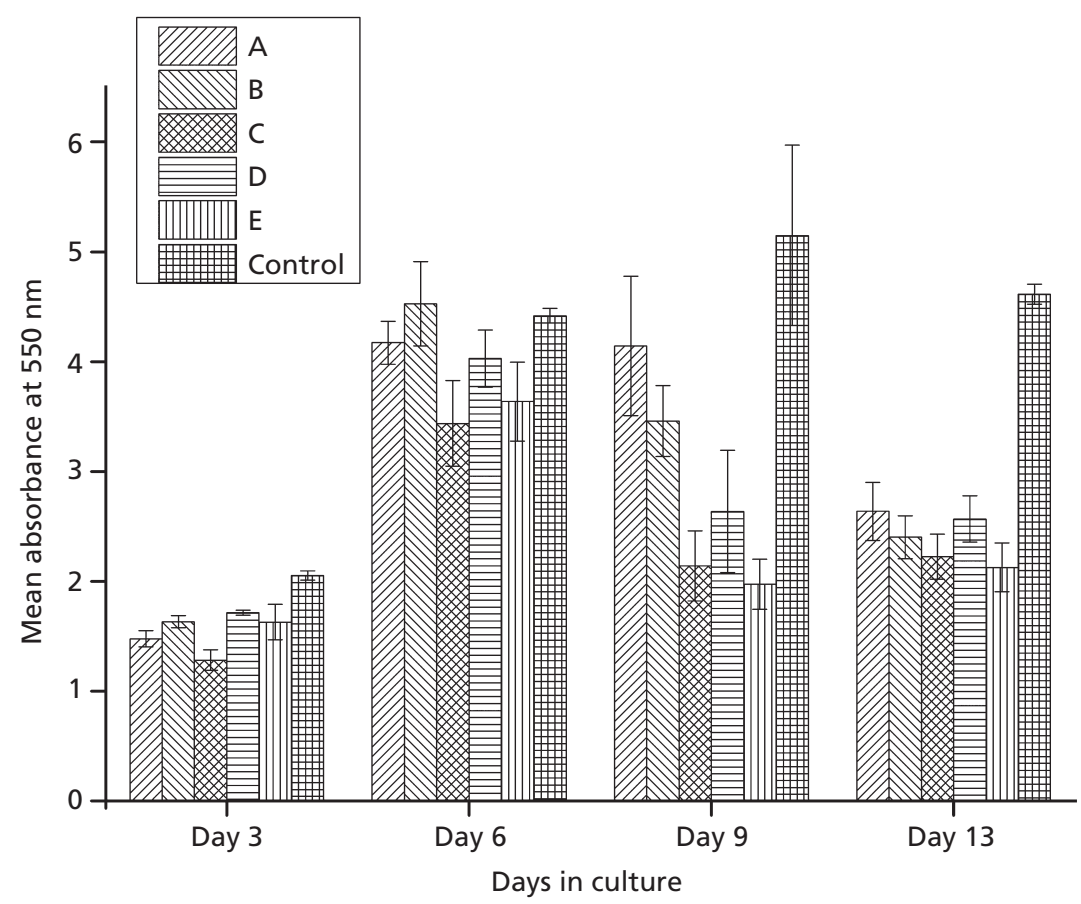

Figure 7. MTT results for cells remaining in wells

from a moulding pressure of $2 \times 10^{6} \mathrm{~kg} / \mathrm{m}^{2}$ were considered more suited to a BGS and therefore taken forward for extrusion.

Two pastes were formulated and exhibited a satisfactory quality of extrusion. Paste 1 with a mix of small and large particle sizes (HAP 100 and HAP 200) was found to flow more readily and hence required a lower percentage of binder and kneading water. The extruded samples A and B had a wall porosity of $15 \%$, D and E had 22\% and C had 33\%. A negative relationship was observed between wall porosity and compressive strength for die 1 samples A, C and D $\left(r^{2}=0.957\right)$ as denoted by a solid line in Figure 9 but no obvious relationship exists between samples B and E. In terms of 


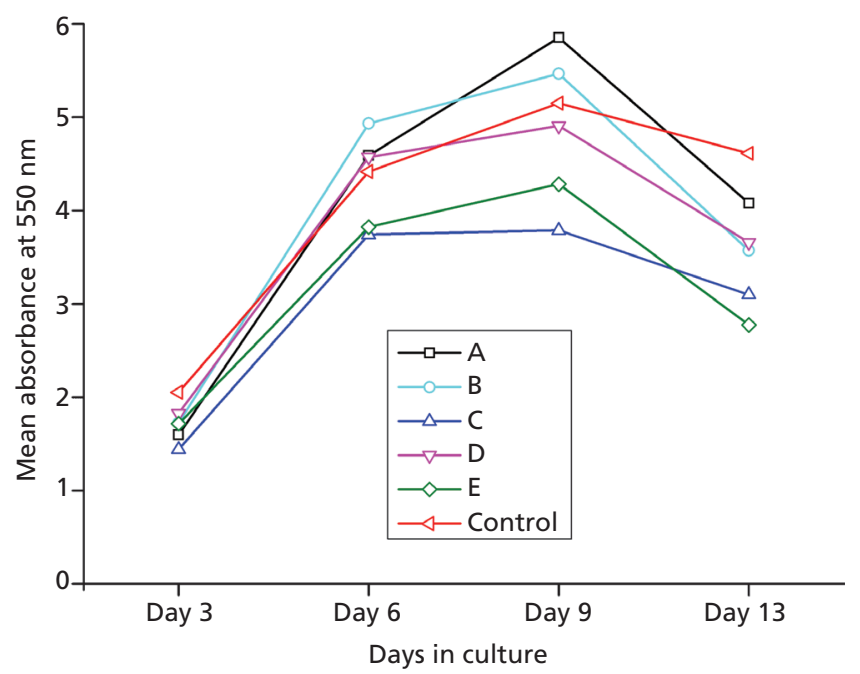

Figure 8. Summed MTT results from samples and wells

compressive modulus, there is a negative relationship with porosity for $\mathrm{A}, \mathrm{C}$ and $\mathrm{D}\left(r^{2}=0.934\right)$ and it is possible to assume a similar relationship for samples B and E (dashed red line in Figure 9). This demonstrates that samples from die 2 have a higher compressive modulus than die 1 . There is also a negative relationship between porosity and bending modulus (solid line with $r^{2}=0.999$ ) as shown in Figure 9. Similarly there is negative relationship between bending strength and porosity although it is not linear.

The high shrinkage of HA (17\%-29\%) compared with materials more commonly used in this process such as cordierite (13.5\%$17 \cdot 4 \%)^{54}$ makes the production of crack-free samples demanding. The compressive strength and modulus achieved by these HA monoliths are excellent given their high level of overall porosity $(54.4 \%-63 \cdot 1 \%)$. The compressive strength for samples A, B, D and $\mathrm{E}$ ranged from 233 to $265 \mathrm{MPa}$ which are comparable with cortical bone. Sample $\mathrm{C}$ with high porosity walls had a compressive strength of $142 \mathrm{MPa}$ in the lower range of cortical bone.

A recent review of BGS mechanical properties highlights the uniqueness of this research and the ability for monoliths to deliver high strength and porosity. ${ }^{24}$ Other researchers have produced high-strength HA but with lower levels of porosity. ${ }^{55,56}$ This is a function of the ordered structure of the extruded monoliths that have exceptional strength in their primary axis. The repetitive array of porosity may offer significant advantages leading to rapid vascularisation of the graft after implantation. If the cells are aligned with the flow of blood at the graft site it would enable blood and cells to rapidly infiltrate and begin the process of healing.

The compressive modulus for scaffolds A, B, D and E ranged from 3.9 to $4.4 \mathrm{GPa}$ and although lower than cortical bone (5-25 GPa) does make these suitable for demanding, load-bearing applications. Bending strength varied from 33 to $46 \mathrm{MPa}$, which is again comparable with other work. ${ }^{55,56}$ In this case, higher porosity is related to lower bending strength. Although these results demonstrate excellent mechanical properties, it is not possible to determine their suitability for large, load-bearing implants without further testing to establish fracture toughness, tensile and shear strength. These were not measured due to the small size of the samples. Future work will concentrate on manufacturing larger HA monoliths that can be characterised more fully for their suitability in indications such as lumbar interbody fusion and repair of long bone segmental defects.

The MTT results highlight that MG63 cells proliferate well on each sample type. There was a decrease in growth rate between days 9 and 13 , which reflects the length of culture time as these cells are known to change their proliferation rate in long-term culture. The graph of summed MTT results demonstrates that samples A and B (paste 1) have a greater number of cells in culture than the control up to day 9. Samples C, D and E (paste 2) have less cells in culture than the control. Thus paste 1 performs marginally better than paste 2 in terms of cell proliferation. The highly porous sample $\mathrm{C}$ performs worst overall biologically. However, the results are inconclusive and demonstrate little difference across the samples. This highlights the limitations with two-dimensional (2D) cell culture testing for comparison of 3D structures.

The biomaterial chosen for the extrusion experiments was HA, which has been used extensively in the clinical setting for many years. However, recent advice from clinicians has made it apparent that HA degrades too slowly in vivo and is considered impractical. This was demonstrated by an in vivo study that followed up the implantation of porous HA blocks into humans over 109 months and found them to be virtually unchanged. ${ }^{34}$ Thus, a commercial BGS is likely to make use of a biphasic calcium phosphate (BCP) that contains a combination of HA and TCP or an ion-substituted HA. Both will degrade relatively more quickly in vivo and have greater osteoinductive potential. The use of TCP may reduce the overall mechanical properties although ion-substituted HA has been reported to reduce degradation time and increase strength. ${ }^{57-61}$ Recent work demonstrated that electrical polarisation of porous HA has a significant effect on osteogenic cell activity and may prove beneficial for HA monoliths. ${ }^{62}$ Overall, the HA used in this study was found to be phase pure by XRD and its use has provided a useful benchmark material. Further work will examine the use of more degradable and osteoinductive materials.

The monoliths fabricated to date have enormous potential to be used as BGSs and later in BTE. These samples demonstrate many significant benefits over the existing market offerings including high strength and ordered and aligned porosity that will make these ideal for both BTE and as a delivery vehicle for osteogenic materials, for example, demineralised bone matrix (DBM).

\section{Conclusions}

Hydroxyapatite monoliths have been manufactured using an extrusion process adapted from production of ceramic exhaust 
Bioinspired, Biomimetic and Nanobiomaterials Volume 4 Issue BBN1
High-strength scaffolds for bone

regeneration

Meredith and Mallick
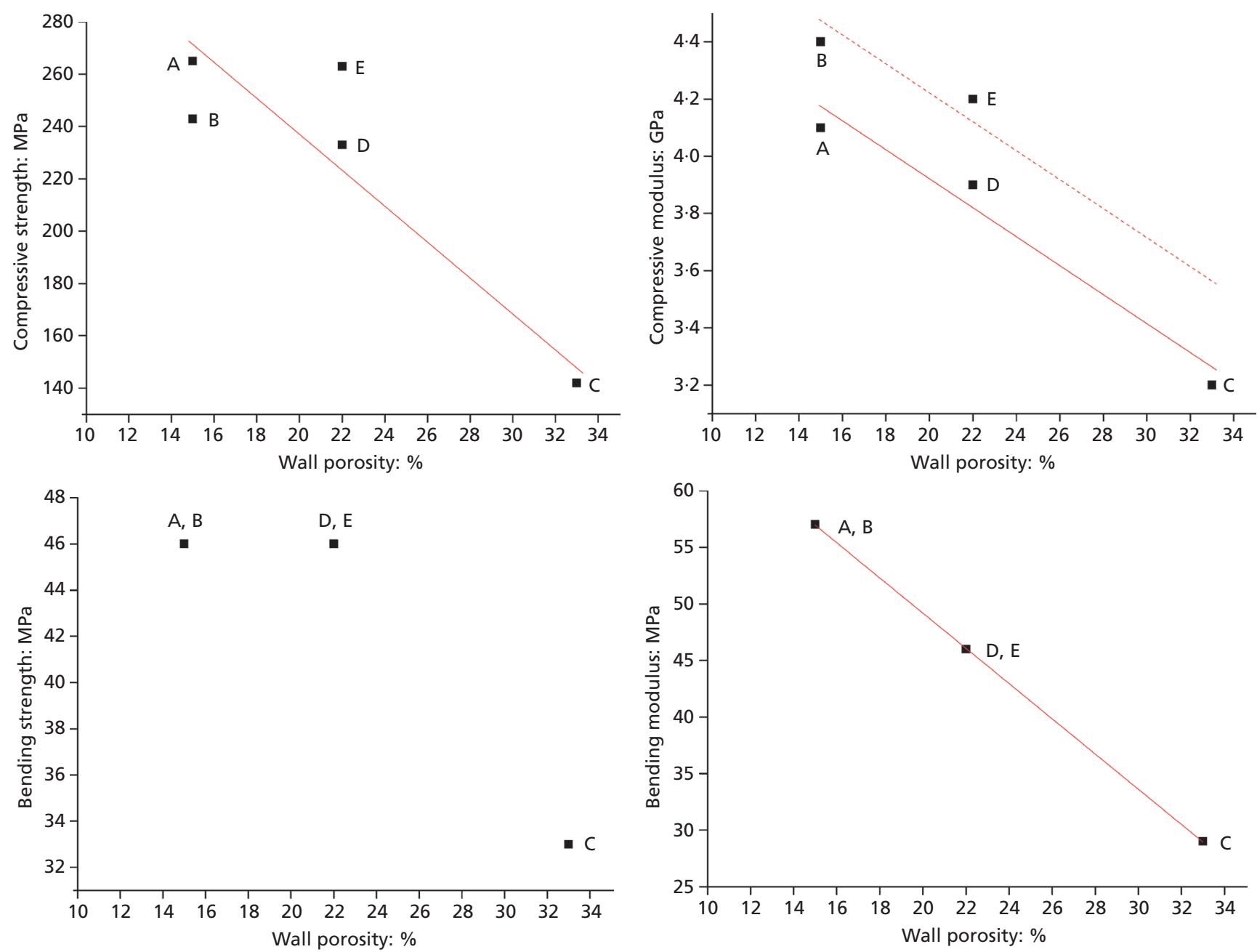

Figure 9. A comparison between wall porosity and mechanical properties for all extruded HA samples

catalysts. Five different samples were produced with differing WT, $\mathrm{CP}$ and raw material. Primary axis compressive strength ranged from 142 to $265 \mathrm{MPa}$ and compressive modulus from 3.9 to 4.4 $\mathrm{GPa}$. These values are in line with cortical bone and are exceptional given the bulk porosity of the samples varied from 54.4\%-63.1\%. All samples supported the proliferation of MG63 cells with no significant difference between each sample. It is expected that calcium phosphate-based extruded monoliths will provide a possible alternative to autograft and allograft for large structural bone defects.

\section{Acknowledgements}

Dr James Meredith would like to thank Dr Kajal Mallick for his guidance and tireless work in this field, the Engineering and Physical Sciences Research Council (EPSRC, EP/G049971/1), their industrial collaborators and Dr Rosemary Bland and Jeanette Bennett at Warwick Biological Sciences.

\section{REFERENCES}

1. Kanczler, J. M.; Oreffo, R. O. C. Osteogenesis and angiogenesis: the potential for engineering bone. European Cells and Materials 2008, 15, 100-114.

2. Finkemeier, C. G. Bone-grafting and bone-graft substitutes. The Journal of Bone and Joint Surgery. American Volume 2002, 84 (3), 454-464.

3. Porter, B. D.; Oldham, J. B.; He, S. L., et al. Mechanical properties of a biodegradable bone regeneration scaffold. Journal of Biomechanical Engineering 2000, 122 (3), 286-288.

4. Clauss, M.; Luem, M.; Ochsner, P. E.; Ilchmann, T. Fixation and loosening of the cemented Muller straight stem: a longterm clinical and radiological review. The Journal of Bone and Joint Surgery. British Volume 2009, 91-B (9), 1158-1163.

5. Johnsen, S. P.; Sorensen, H. T.; Lucht, U., et al. Patient-related predictors of implant failure after primary total hip replacement in the initial, short- and long-terms: a nationwide Danish 
Bioinspired, Biomimetic and Nanobiomaterials Volume 4 Issue BBN1
High-strength scaffolds for bone

regeneration

Meredith and Mallick follow-up study including 36984 patients. The Jornal of Bone and Joint Surgery. British Volume 2006, 88-B (10), 1303-1308

6. Hench, L. L. (ii) The challenge of orthopaedic materials. Current Orthopaedics 2000, 14 (1), 7-15.

7. Hubble, M. J. W. Bone transplantation. Current Orthopaedics 2001, 15 (3), 199-205.

8. Bragdon, B.; Moseychuk, O.; Saldanha, S., et al. Bone morphogenetic proteins: a critical review. Cellular Signalling 2011, 23 (4), 609-620.

9. Habibovic, P.; Barralet, J. E. Bioinorganics and biomaterials: bone repair. Acta Biomaterialia 2011, 7 (8), 3013-3026.

10. Hing, K. A. Bone repair in the twenty-first century: biology, chemistry or engineering? Philosophical Transactions of the Royal Society of London Series A: Mathematical, Physical and Engineering Sciences 2004, 362 (1825), 2821-2850.

11. Giannoudis, P. V.; Dinopoulos, H.; Tsiridis, E. Bone substitutes: an update. Injury 2005, 36 (3_suppl_1), S20-S27.

12. Livingston, T.; Ducheyne, P.; Garino, J. In vivo evaluation of a bioactive scaffold for bone tissue engineering. Journal of Biomedical Materials Research 2002, 62 (1), 1-13.

13. Barriga, A.; Díaz-de-Rada, P.; Barroso, J. L., et al. Frozen cancellous bone allografts: positive cultures of implanted grafts in posterior fusions of the spine. European Spine Journal 2004, 13 (2), 152-156.

14. Bucholz, R. W. Nonallograft osteoconductive bone graft substitutes. Clinical Orthopaedics and Related Research 2002, 395, 44-52.

15. Dimitriou, R.; Jones, E.; McGonagle, D.; Giannoudis, P. V. Bone regeneration: current concepts and future directions. BMC Medicine. 2011, 9, 66.

16. Van der Stok, J.; Van Lieshout, E. M. M.; El-Massoudi, Y.; Van Kralingen, G. H.; Patka, P. Bone substitutes in the Netherlands - a systematic literature review. Acta Biomaterialia 2011, 7 (2), 739-750.

17. Frost \& Sullivan Research Service. European Market for Bone Grafts and Bone. 2008 Contract No.: M1B8-54.

18. Frost \& Sullivan Research Service. U.S. Bone Grafts and Bone Graft Substitutes Markets. 2007 Contract No.: F875-54.

19. Kai-Uwe, L.; Donald, L. W.; Debra, J. T.; Joseph, D. G.; Michael, J. Y.; David, E. A. Tissue Engineering and Biodegradable Equivalents - Scientific and Clinical Applications. Fort Worth, TX: Marcel Dekker Inc., 2002.

20. Greenwald, A. S.; Boden, S. D.; Goldberg, V. M., et al. Bonegraft substitutes: facts, fictions, and applications. The Journal of Bone and Joint Surgery. American Volume 2001, 83-A (2_suppl_2), S98-S103.

21. Yuan, H.; Fernandes, H.; Habibovic, P., et al. Osteoinductive ceramics as a synthetic alternative to autologous bone grafting. Proceedings of the National Academy of Sciences of the United States of America 2010, 107 (31), 13614-13619.

22. Kolambkar, Y. M.; Dupont, K. M.; Boerckel, J. D., et al. An alginate-based hybrid system for growth factor delivery in the functional repair of large bone defects. Biomaterials 2011, 32 (1), 65-74.

23. Vaz, K.; Verma, K.; Protopsaltis, T., et al. Bone grafting options for lumbar spine surgery: a review examining clinical efficacy and complications. The International Journal of Spine Surgery 2010, 4 (3), 75-86.

24. Wagoner Johnson, A. J.; Herschler, B. A. A review of the mechanical behavior of $\mathrm{CaP}$ and $\mathrm{CaP} /$ polymer composites for applications in bone replacement and repair. Acta Biomaterialia 2011, 7 (1), 16-30.

25. Hasirci, V.; Lewandrowski, K.; Gresser, J. D.; Wise, D. L.; Trantolo, D. J. Versatility of biodegradable biopolymers: degradability and an in vivo application. Journal of Biotechnology 2001, 86 (2), 135-150.

26. Liebschner, M. A. K. Biomechanical considerations of animal models used in tissue engineering of bone. Biomaterials 2004, 25 (9), 1697-1714.

27. Wang, X.; Ni, Q. Determination of cortical bone porosity and pore size distribution using a low field pulsed NMR approach. Journal of Orthopaedic Research 2003, 21 (2), 312-319.

28. Zhang, F.; Chang, J.; Lu, J.; Lin, K.; Ning, C. Bioinspired structure of bioceramics for bone regeneration in load-bearing sites. Acta Biomaterialia 2007, 3 (6), 896-904.

29. Salgado, A. J.; Coutinho, O. P.; Reis, R. L. Bone tissue engineering: state of the art and future trends. Macromolecular Bioscience 2004, 4 (8), 743-765.

30. Leong, K. F.; Cheah, C. M.; Chua, C. K. Solid freeform fabrication of three-dimensional scaffolds for engineering replacement tissues and organs. Biomaterials 2003, 24 (13), 2363-2378.

31. Burg, K. J. L.; Porter, S.; Kellam, J. F. Biomaterial developments for bone tissue engineering. Biomaterials 2000, 21 (23), 2347-2359.

32. Barrère, F.; Mahmood, T. A.; de Groot, K.; van Blitterswijk C. A. Advanced biomaterials for skeletal tissue regeneration: instructive and smart functions. Materials Science and Engineering: R: Reports 2008, 59 (1-6), 38-71.

33. Navarro, M.; del Valle, S.; Martínez, S., et al. New macroporous calcium phosphate glass ceramic for guided bone regeneration. Biomaterials 2004, 25 (18), 4233-4241.

34. Sachlos, E.; Czernuszka, J. T. Making tissue engineering scaffolds work. Review: the application of solid freeform fabrication technology to the production of tissue engineering scaffolds. European Cells \& Materials 2003, 5, 29-39.

35. von Doernberg, M.-C.; von Rechenberg, B.; Bohner, M., et al. In vivo behavior of calcium phosphate scaffolds with four different pore sizes. Biomaterials 2006, 27 (30), 5186-5198.

36. Babis, G. C.; Soucacos, P. N. Bone scaffolds: the role of mechanical stability and instrumentation. Injury 2005, 36 (4 suppl_1), S38-S44.

37. Dorozhkin, S. V. Amorphous calcium (ortho)phosphates. Acta Biomaterialia 2010, 6 (12), 4457-4475. 
Bioinspired, Biomimetic and Nanobiomaterials Volume 4 Issue BBN1
High-strength scaffolds for bone

regeneration

Meredith and Mallick
38. Verron, E.; Khairoun, I.; Guicheux, J.; Bouler, J.-M. Calcium phosphate biomaterials as bone drug delivery systems: a review. Drug Discovery Today 2010, 15 (13-14), 547-552.

39. Habibovic, P.; de Groot, K. Osteoinductive biomaterials - properties and relevance in bone repair. Journal of Tissue Engineering and Regenerative Medicine 2007, 1 (1), 25-32.

40. Habibovic, P.; Gbureck, U.; Doillon, C. J., et al. Osteoconduction and osteoinduction of low-temperature 3D printed bioceramic implants. Biomaterials 2008, 29 (7), 944-953.

41. Fellah, B. H.; Gauthier, O.; Weiss, P.; Chappard, D.; Layrolle, P. Osteogenicity of biphasic calcium phosphate ceramics and bone autograft in a goat model. Biomaterials 2008, 29 (9), $1177-1188$

42. Li, X.; van Blitterswijk, C. A.; Feng, Q.; Cui, F.; Watari, F. The effect of calcium phosphate microstructure on bone-related cells in vitro. Biomaterials 2008, 29 (23), 3306-3316.

43. Habibovic, P.; Yuan, H.; van der Valk, C. M., et al. 3D microenvironment as essential element for osteoinduction by biomaterials. Biomaterials 2005, 26 (17), 3565-3575.

44. Li, J.; Habibovic, P.; Yuan, H., et al. Biological performance in goats of a porous titanium alloy-biphasic calcium phosphate composite. Biomaterials 2007, 28 (29), 4209-4218.

45. LeGeros, R. Z. Calcium phosphate-based osteoinductive materials. Chemical Reviews 2008, 108 (11), 4742-4753.

46. Bagley, R. D., Corning Glass Works. Extrusion Apparatus for Forming Thin-Walled Honeycomb Structures 1975.

47. Michael, S.; Paolo, C. Cellular Ceramics: Structure, Manufacturing, Properties and Applications. Germany: Willey-VCH Verlag GmbH \& Co., 2005.

48. Forzatti, P.; Ballardini, D.; Sighicelli, L. Preparation and characterization of extruded monolithic ceramic catalysts. Catalysis Today 1998, 41 (1-3), 87-94.

49. Williams, J. L. Monolith structures, materials, properties and uses. Catalysis Today 2001, 69 (1-4), 3-9.

50. Avila, P.; Montes, M.; Miró, E. E. Monolithic reactors for environmental applications: a review on preparation technologies. Chemical Engineering Journal 2005, 109 (1-3), 11-36.

51. Yamamoto, T.; Onga, T.; Marui, T.; Mizuno, K. Use of hydroxyapatite to fill cavities after excision of benign bone tumours: clinical results. The Journal of Bone and Joint Surgery. British Volume 2000, 82-B (8), 1117-1120.

52. Sakai, T.; Ohzono, K.; Nishii, T., et al. Grafting with hydroxyapatite granules for defects of acetabular bone at revision total hip replacement: a minimum ten-year follow-up. The Journal of Bone and Joint Surgery. British Volume 2010, 92-B (9), 1215-1221.

53. Damien, E. R. P. Coralline hydroxyapatite bone graft substitute: a review of experimental studies and biomedical applications. Journal of Applied Biomaterials and Biomechanics 2004, 2 (2), 65-73.

54. Raupp-Pereira, F.; Ribeiro, M. J.; Segadães, A. M.; Labrincha, J. A. Extrusion and property characterisation of waste-based ceramic formulations. Journal of the European Ceramic Society 2007, 27 (5), 2333-2340.

55. Pramanik, S.; Agarwal, A. K.; Rai, K. N.; Garg, A. Development of high strength hydroxyapatite by solid-statesintering process. Ceramics International 2007, 33 (3), 419-426.

56. Akao, M. A. H.; Kato, K. Mechanical-properties of sintered hydroxyapatite for prosthetic applications. Journal of Materials Science 1981, 16, 809-812.

57. Webster, T. J.; Massa-Schlueter, E. A.; Smith, J. L.; Slamovich, E. B. Osteoblast response to hydroxyapatite doped with divalent and trivalent cations. Biomaterials 2004, 25 (11), 2111-2121.

58. Porter, A. E.; Patel, N.; Skepper, J. N.; Best, S. M.; Bonfield, W. Effect of sintered silicate-substituted hydroxyapatite on remodelling processes at the bone-implant interface. Biomaterials 2004, 25 (16), 3303-3314.

59. Hing, K. A.; Revell, P. A.; Smith, N.; Buckland, T. Effect of silicon level on rate, quality and progression of bone healing within silicate-substituted porous hydroxyapatite scaffolds. Biomaterials 2006, 27 (29), 5014-5026.

60. Patel, N.; Best, S. M.; Bonfield, W., et al. A comparative study on the in vivo behavior of hydroxyapatite and silicon substituted hydroxyapatite granules. Journal of Materials Science: Materials in Medicine 2002, 13 (12), 1199-1206.

61. Cox, S. C.; Jamshidi, P.; Grover, L. M.; Mallick, K. K. Preparation and characterisation of nanophase $\mathrm{Sr}, \mathrm{Mg}$, and $\mathrm{Zn}$ substituted hydroxyapatite by aqueous precipitation. Materials Science and Engineering C: Materials for Biological Applications 2014, 35, 106-114.

62. Wang, Z.-G.; Wan, L.-S.; Liu, Z.-M.; Huang, X.-J.; Xu, Z.-K. Enzyme immobilization on electrospun polymer nanofibers: an overview. Journal of Molecular Catalysis B: Enzymatic 2009, 56 (4), 189-195.

\section{WHAT DO YOU THINK?}

To discuss this paper, please email up to 500 words to the managing editor at bbn@icepublishing.com

Your contribution will be forwarded to the author(s) for a reply and, if considered appropriate by the editor-inchief, will be published as a discussion in a future issue of the journal.

ICE Science journals rely entirely on contributions sent in by professionals, academics and students coming from the field of materials science and engineering. Articles should be within 5000-7000 words long (short communications and opinion articles should be within 2000 words long), with adequate illustrations and references. To access our author guidelines and how to submit your paper, please refer to the journal website at www.icevirtuallibrary.com/bbn 